\title{
Bezoars and Surgery
}

\author{
Salih Erpulat Öziș, Hasan Turgut Aydın
}

\section{Dear Editor}

We read the article entitled "Comparison of surgical approaches to acute mechanical intestinal obstruction due to bezoars" published in Turkish Journal of Surgery, 2012; 28 (3):143 -145 by authors Mr. Bozkurt and his colleagues. Our criticism related to the article can be found below.

We did not find any information throughout the article on the type, size, location of bezoars, or the patient's history of previous operations. As is well known bezoars are observed in cases where gastric emptying time is prolonged after surgeries like gastrectomy or vagotomy, pyloric dysfunction or diabetic neuropathy and hypothyroidism, in patients who eat fast, swallow without chewing and excess intake of fiber.

The article does not contain sufficient information on the previously mentioned issues.

Another criticism should be made regarding the surgical technique. As is well known, a surgeon encountering bezoars is expected to first try to milk the bezoars into the cecum. However, we had the impression that in these operations resection or enterotomies have been directly performed without such an attempt.

Another criticism is the point that this article was accepted within 2 days rather than re-evaluation after corrections on these criticisms.

\section{Author's Reply}

Dear Editor

The clarifications we would like to point out regarding criticism on our manuscript published in Turkish Journal of Surgery 2012;28(3):143-145 are listed below.

Our work is primarily on comparison of two different operating procedures used in the treatment of bezoars. Our goal is not to assess etiology; it is stated in the literature that detailed etiological investiga-

Department of General Surgery, Ufuk University Faculty of Medicine, Ankara, Turkey

Address for Correspondence Dr. Salih Erpulat Öziş Department of General Surgery, Ufuk University Faculty of Medicine, Ankara, Turkey Phone.: +90312 2044247

e-mail:

erpulat@yahoo.com

CCopyright 2013 by Turkish Surgical Association

Available online at www.ulusalcerrahidergisi.org tion, the type and size of bezoars have no impact on treatment approaches and is therefore meaningless in our opinion. It is impossible to detect the properties of bezoars prior to an operation. Likewise, patient's hypothyroidism or prior gastric surgeries have no effect on management.

Milking process of bezoars is mentioned for a paragraph in the discussion section and it is accepted as the initial method but as is stated in the literature this is generally not accomplished.

Finally, as stated below our manuscript was not accepted in two days, actually, a correction request was made and accepted thereafter.

We would like to thank the critics for their interest in our article, and the Turkish Journal of Surgery for the opportunity to reply.

M. Abdussamet Bozkurt' ${ }^{1}$ Ali Kocataş², Halil Alış²

'Department of General Surgery, Pervari State Hospital, Siirt, Turkey

2Department of General Surgery, Bakırköy Dr. Sadi Konuk Teaching and Training Hospital, İstanbul, Turkey 


\section{Editor's Reply:}

Dear Reader,

This text was received on July 19, 2012, and was sent back to the author with request of some adjustments by the editorial board and referee after evaluation. Then the authors sent the article back by making the necessary adjustments on 29 July 2012 and on 31 July 2012, the article has been accepted for publication.
The printed arrival date of this article on the September 2012 issue of our journal should be corrected as "July 19, 2012" rather than "29 July 2012". We will correct the error that inadvertently leads to misunderstandings. On the other hand, we would like to thank our referees for making a quick and high-scale assessment of this article as well as the authors who fulfilled the required adjustments in a timely manner. 